\title{
Şirketler Ligine Katılan İş Görenlerin Örgütsel Streslerinin Belirlenmesi
}

DOI: $10.26466 /$ opus.581146

\author{
$*$ \\ Arda Öztürk * - Osman Tolga Togo** \\ *Dr. Öğr. Üyesi, Pamukkale Üniversitesi, Spor Bilimleri Fakültesi, Denizli/Türkiye \\ E-Posta: ardaozturk82@hotmail.com \\ ORCID: 0000-0003-3360-3046 \\ **Dr. Öğr. Üyesi, Harran Üniversitesi, Beden Eğitimi ve Spor Yüksekokulu, Ş.urfa/ Türkiye \\ E-Posta: tolgatogo@gmail.com \\ ORCID: $\underline{0000-0002-0471-4436}$
}

\section{Öz}

Bu araştırmanın amacl, şirketler ligi basketbol spor organizasyonuna katılan bireylerin Örgütsel Stres düzeylerinin belirlenmesidir. Çalışmanın araştırma grubunu; İstanbul İng bank ve Denizbank bünyesinde yer alan ve şirketler ligi basketbol spor organizasyonuna katılan toplam 110 kişi ( 39 Kadın, 71 Erkek) oluşturmuştur. Araştırmada veri toplama aracı olarak; Theorell ve arkadaşları tarafindan 1988 yılında geliştirilen, Yıldırım ve arkadaşları tarafından 2011 yılında Türkçeye çevrilen 14 soru ve üç alt boyuttan oluşan anketi kullanılmıştır. Elde edilen verilerin normalliği test edilip, verilerin normal dağıllım göstermediği görülmüş, bunun sonucunda araştırma analizi için İkili karşılaştırmalarda Mann Whitney U Test, çoklu karşılaştırmalarda Kruskal Wallis Test uygulanmıştır. Verilerin analizinde, İstatistiki sonuçlar $p<0,05$ önem düzeyinde anlamlı bulunmuştur. Araştırma sonucunda, Örgütsel Stres ölçeği; cinsiyet değişkeni ve eğitim durumu değiş̧kenine göre Karar Verme alt boyutunda, cinsiyet değişkeninde erkeklerin, eğitim durumu değişkeninde ise Yüksek Lisans mezunlarının lehinde anlaml farklilı̆̆ın oluştuğu görülmüştür. Medeni durum değişkenine göre yapılan Mann Whitney-U testi sonucunda, bekar bireylere göre evli bireylerin lehine istatistiksel açıdan anlamlı bir farklllik bulunmuştur $(P<0.05)$. Medeni durum değişkenine göre anlaml farkm evli bireylerin bu yükü birlikte üstesinde gelme çabası içinde olduğunu ve özellikle de "iş yükü" alt boyutunda bu farklılı̆̆ın ön plana çıtığın göstermektedir. Yaş değişkenine göre yapılan Kruskall Wallis testi sonucunda istatistiksel açıdan anlamlı bir farklılık bulunmuştur $(P<0.05)$.

Anahtar Kelimeler: Basketbol, Örgütsel Stres, Şirketler Ligi. 


\title{
Determination of Organizational Stresses For Employees Participated in Corporate League
}

\begin{abstract}
The aim of this study is to determine the Organizational Stress levels of the individuals participating in the basketball sport organization of the league of companies. The research group of the study; A total of 110 people (39 females, 71 males) participated in the basketball sport organization of the Istanbul ING Bank and Denizbank. As a data collection tool; The questionnaire, which was developed by Theorell et al. In 1988 and which was translated into Turkish by Yildirm et al. In 2011, consisted of 14 questions and three sub-dimensions. The results of the data were tested and the data were not normal. As a result, Mann Whitney U Test was used for the paired comparisons and Kruskal Wallis test was used for multiple comparisons. In the analysis of the data, statistical results were found significant at $p<0.05$ significance level. At the end of the research, Organizational Stress Scale; In the Decision Making sub-dimension according to the gender variable and educational status variable, it was seen that there was a significant difference in the gender variable in the variables of gender and in the educational variable variable in favor of the MA graduates. According to the Mann-Whitney-U test according to the marital status variable, a statistically significant difference was found in favor of married individuals according to single individuals $(P<0.05)$. The significant difference between marital status variable shows that married individuals are in an effort to overcome this burden together and this difference comes to the fore especially in the work load sub-dimension. Kruskall Wallis test performed according to age variables revealed a statistically significant difference $(P<0.05)$.
\end{abstract}

Keywords: Basketball, Organizational Stress, Business League. 


\section{Giriş}

Günümüz toplumunda insanların büyük bir kısmı stres altında yaşamaktadırlar. Çalışma hayatı da bu durumun en büyük sebeplerindendir. Bankalar, kaçınılmaz bir durum olan stresin negatif etkilerini durdurabilmek ve yok edebilmek için stresi önlemek için çeşitli yöntemler geliştirmek durumundadırlar. Bunun için de örgütsel stresin sebeplerinin bulunması ve tespit edilmesi gerekmektedir. Lazarus, stresi organizmanın gereksinimlerinin, organizmanın kaynaklarını aştığında ortaya çıkan durum olarak tanımlamıştır (Ekmekçi,2008). Stres, hayatın vazgeçilmez bir parçasıdır. Çünkü insana çevresindeki uyaranlar karşısında daha iyi davranma olanağ 1 verir (Eren, 2000).

“Örgütsel stres, kişinin çevre ile ilişkisinin sonucunda kişiye fazla zihinsel veya fiziksel istekler yükleyen dış çevreye karşı vermiş olduğu bir tepkidir" (Akgündüz, 2006). İş ortamında iş görenin kendisinden beklenenleri yerine getirme sürecinde hissetmiş olduğu fiziksel ve zihinsel baskılar sonucunda ortaya çıktığı söylenebilir. Yılmaz (2007)'ye göre ise çal1şanlar üzerinde örgütsel stresin negatif etkiler oluşturarak iş yerindeki performanslarını azalttığı ve iş ortamında kendilerinin ve iş arkadaşlarının güvenliğini negatif olarak etkilediğini belirtmektedir.

Stresin insanlar üzerinde normal işlevleri olumsuz yönde etkileyerek sıkıntı ve endişe yaratabildiği ve çeşitli sağlık sorunlarına neden olabildiği bilinmektedir (Eskin, 2013). Diğer yandan stres her zaman olumsuz, zarar verici olmak durumunda değildir. Stres eğer başarı ve sonrasında mutluluğa sebebiyet veriyorsa olumlu, zarara yol açıyor ve mutsuzluğa sebebiyet veriyorsa olumsuz stres olarak nitelendirilmektedir (Aydın, 2004).Stres, yüksek benlik saygısı, yüksek doyum düzeyi ile ilişkilidir (Arıkan,2019).

Bireysel ve örgütsel verimliliği artırmak ve yukarıda da anlatılan negatif durumlardan kurtulabilmek için, iş yaşamındaki stres seviyesinin kontrol edilmesi gerekmektedir. Bu yüzden stresli çalışma hayatı, çalışanların daha sinirli olmaları ve başkaları ile sorun yaşamaları gibi durumları ortaya çıkarmaktadır. (Soysal, 2009).

Bankada çalışan bireyler, çalışma ortamında iş yetiştirme durumlarına göre, kendilerini baskı altında çalışmaya zorlamaktadırlar. Bu baskı sebebiyle de fiziksel, psikolojik geçişler yaşamaktadırlar. Bu durumda katılım 
gösterdikleri spor organizasyonunda iş yerindeki stres ortamindan uzaklaşıp hem fiziksel hem de zihinsel olarak rahatlama gösterebilecekleri düşünülmektedir. Bu çalışmada İng Bank ve Denizbank bankalarının farklı birimlerinde çalışan spor organizasyonuna katılan bireylerin algılanan örgütsel stres düzeylerinin belirlenmesi ve bazı faktörler ile ilişkisinin araştırılması amaçlanmıştır.

\section{Yöntem}

\section{Araştırmanın Amacı}

Bu araştırmada, İng Bank ve Denizbank bankalarının farklı birimlerinde çalışan spor organizasyonuna katılan bireylerin algılanan örgütsel stres düzeylerinin belirlenmesi ve bazı faktörler ile ilişkisinin incelenmesi amaçlanmıştır.

\section{Araştırmanın Yöntemi}

Araştırmanın evrenini; İng bank ve Denizbank İstanbul genel müdürlügünde farklı birimlerde çalışan tüm bireyler oluşturmakta olup, örneklemini ise, İng bank ve Denizbank İstanbul genel müdürlüğünde farklı birimlerde çalışan ve spor organizasyonlarına katılmış 110 kişi oluşturmaktadir.

\section{Veri Toplama Aracı}

Bu çalışma ile Theorell ve arkadaşları tarafından 1988 yılında geliştirilen, Yıldırım ve arkadaşları tarafından 2011 yılında Türkçeye çevrilen 14 soru ve üç alt boyuttan oluşan anketi kullanılmıştır. Anket Türkçeye çevrilip, uzman görüşleri ile birlikte yeniden düzenlenerek hazırlanmıştır. Analize alınan maddelerin 14'ünün öz değeri 1'den büyük 4 faktör altında toplanmıştır. Birinci faktör 14., 15., 17., 13., 16. ve 12. maddelerden, ikinci faktör 2., 1. ve 3. maddelerden, üçüncü faktör 7., 8. ve 6. maddelerden, dördüncü faktörün ise 10. ve 11. maddelerden oluştuğu görülmektedir. Faktörlerin Cronbach's Alpha iç tutarlılık değerleri incelendiğinde birinci faktör için (Sosyal destek alt boyutu $\alpha=0.80$ ), İkinci faktör için (İş Yükü alt boyutu 
$\alpha=0.60$ ), üçüncü faktör için (Beceri Kullanımı alt boyutu $\alpha=0.71$ ), dördüncü faktör için (Karar Verme alt boyutu $\alpha=0.78$ ) olarak belirlenmiştir. Toplam ölçeğin Cronbach's Alpha iç tutarlılık değerleri ise $(\alpha=0.79)$ olarak bulunmuştur.

\section{Verilerin İstatistiksel Analizi}

Elde edilen verilerin analizi SPSS 21.0 paket programında yapılmıştır. Örgütsel Stres ölçeğinden elde edilen verilerin yüzde ve frekans dağılımları çıkarılmıştır Örgütsel Stres ölçeğinden elde edilen verilerin normalliği ve homojen dağılıp dağılmadığı belirlendikten sonra verilerin normal dağ1lım göstermediği görülmüş, bunun sonucunda araştırma analizi için İkili karşılaştırmalarda Mann Whitney U Test, çoklu karşılaştırmalarda Kruskal Wallis Test uygulanmıştır. Verilerin analizi \%95 güven aralığında, $\mathrm{p}<0.05$ anlamlılık düzeyinde değerlendirilmiştir.

\section{Bulgular}

Tablo 1. Örgütsel Stres Ölçeği puanlarının medeni durum değişkenine göre Mann Whitney U testi sonuçlarn

\begin{tabular}{|c|c|c|c|c|c|c|}
\hline Alt Boyutlar & $\begin{array}{l}\text { Medeni Du- } \\
\text { rum }\end{array}$ & $\mathbf{N}$ & $\begin{array}{c}\text { Sira Orta- } \\
\text { lamas1 }\end{array}$ & $\begin{array}{c}\text { Sira Top- } \\
\text { lamı }\end{array}$ & U & $\mathbf{P}$ \\
\hline İş Yükü & $\begin{array}{c}\text { Bekar } \\
\text { Evli }\end{array}$ & $\begin{array}{l}57 \\
53\end{array}$ & $\begin{array}{l}43,82 \\
68,06\end{array}$ & $\begin{array}{l}2498,00 \\
3607,00\end{array}$ & 845,00 & , 000 \\
\hline $\begin{array}{l}\text { Beceri Kulla- } \\
\text { nımı }\end{array}$ & $\begin{array}{c}\text { Bekar } \\
\text { Evli }\end{array}$ & $\begin{array}{l}57 \\
53\end{array}$ & $\begin{array}{l}55,20 \\
55,82\end{array}$ & $\begin{array}{l}3146,50 \\
2958,50\end{array}$ & 1493,50 & ,917 \\
\hline Karar Verme & $\begin{array}{c}\text { Bekar } \\
\text { Evli }\end{array}$ & $\begin{array}{l}57 \\
53 \\
\end{array}$ & $\begin{array}{l}54,20 \\
56,90 \\
\end{array}$ & $\begin{array}{l}3089,50 \\
3015,50 \\
\end{array}$ & 1436,50 & ,645 \\
\hline Sosyal Destek & $\begin{array}{c}\text { Bekar } \\
\text { Evli }\end{array}$ & $\begin{array}{l}57 \\
53\end{array}$ & $\begin{array}{l}54,93 \\
56,11 \\
\end{array}$ & $\begin{array}{l}3131,00 \\
2974,00 \\
\end{array}$ & 1478,00 & 844 \\
\hline Toplam & $\begin{array}{c}\text { Bekar } \\
\text { Evli }\end{array}$ & $\begin{array}{l}57 \\
53\end{array}$ & $\begin{array}{l}48,88 \\
62,62 \\
\end{array}$ & $\begin{array}{l}2786,00 \\
3319,00 \\
\end{array}$ & 1133,00 &, $023^{*}$ \\
\hline
\end{tabular}

Tablo 1'de görüldüğü gibi, araştırmaya katılanların Örgütsel Stres Ölçeğinden almış oldukları puanların, medeni durum değişkenine göre yapilan Mann Whitney-U testi sonucunda, bekar bireylere göre evli bireylerin lehine istatistiksel açıdan anlamlı bir farklılık bulunmuştur $(\mathrm{P}<0.05)$. 
Ayrıca Örgütsel Stres Ölçeği İş Yükü alt boyutunda yine evli bireyler lehine anlamlı farklılık bulunmuştur.

Tablo 2. Örgütsel Stres Ölçeği puanlarnnı cinsiyet ve eğitim durumu değgişkenine göre Mann Whitney $U$ testi sonuçlan

\begin{tabular}{|c|c|c|c|c|c|c|}
\hline Alt Boyutlar & Cinsiyet & $\mathbf{N}$ & $\begin{array}{c}\text { Sira Ortala- } \\
\text { masi }\end{array}$ & $\begin{array}{c}\text { Sira Top- } \\
\text { lamı }\end{array}$ & U & $\mathbf{P}$ \\
\hline İş Yükü & $\begin{array}{l}\text { Kadın } \\
\text { Erkek }\end{array}$ & $\begin{array}{l}39 \\
71\end{array}$ & $\begin{array}{l}58,09 \\
54,08\end{array}$ & $\begin{array}{l}2265,50 \\
3839,50\end{array}$ & 1283,50 & ,516 \\
\hline $\begin{array}{c}\text { Beceri Kulla- } \\
\text { nımı }\end{array}$ & $\begin{array}{l}\text { Kadın } \\
\text { Erkek }\end{array}$ & $\begin{array}{l}39 \\
71\end{array}$ & $\begin{array}{l}53,14 \\
56,80\end{array}$ & $\begin{array}{l}2072,50 \\
4032,50\end{array}$ & 1292,50 & ,556 \\
\hline Karar Verme & $\begin{array}{l}\text { Kadın } \\
\text { Erkek }\end{array}$ & $\begin{array}{l}39 \\
71\end{array}$ & $\begin{array}{l}47,35 \\
59,98\end{array}$ & $\begin{array}{l}1846,50 \\
4258,50\end{array}$ & 1066,50 & ,039* \\
\hline $\begin{array}{c}\text { Sosyal Des- } \\
\text { tek }\end{array}$ & $\begin{array}{l}\text { Kadın } \\
\text { Erkek }\end{array}$ & $\begin{array}{l}39 \\
71\end{array}$ & $\begin{array}{l}54,76 \\
55,91\end{array}$ & $\begin{array}{l}2135,50 \\
3969,50\end{array}$ & 1355,50 & ,854 \\
\hline \multirow[t]{2}{*}{ Toplam } & $\begin{array}{l}\text { Kadın } \\
\text { Erkek }\end{array}$ & $\begin{array}{l}39 \\
71\end{array}$ & $\begin{array}{l}50,00 \\
58,82\end{array}$ & $\begin{array}{l}1950,00 \\
4155,00\end{array}$ & 1170,00 & , 179 \\
\hline & $\begin{array}{l}\text { Eğitim Du- } \\
\text { rumu }\end{array}$ & $\mathbf{N}$ & $\begin{array}{l}\text { Sira Ortala- } \\
\text { masi }\end{array}$ & $\begin{array}{l}\text { Sira Top- } \\
\text { lamı }\end{array}$ & U & $\mathbf{P}$ \\
\hline İş Yükü & $\begin{array}{l}\text { Lisans } \\
\text { Y.Lisans }\end{array}$ & $\begin{array}{l}76 \\
34\end{array}$ & $\begin{array}{l}56,82 \\
52,54\end{array}$ & $\begin{array}{l}4318,50 \\
1786,50\end{array}$ & 1191,50 & ,503 \\
\hline $\begin{array}{c}\text { Beceri Kulla- } \\
\text { nımı }\end{array}$ & $\begin{array}{l}\text { Lisans } \\
\text { Y.Lisans }\end{array}$ & $\begin{array}{l}76 \\
34\end{array}$ & $\begin{array}{l}56,44 \\
53,40\end{array}$ & $\begin{array}{l}4289,50 \\
1815,50\end{array}$ & 1220,50 & 636 \\
\hline Karar Verme & $\begin{array}{l}\text { Lisans } \\
\text { Y.Lisans }\end{array}$ & $\begin{array}{l}76 \\
34\end{array}$ & $\begin{array}{l}50,17 \\
67,41\end{array}$ & $\begin{array}{l}3813,00 \\
2292,50\end{array}$ & 887,00 &, $006^{*}$ \\
\hline Sosyal Des- & $\begin{array}{l}\text { Lisans } \\
\text { Y.Lisans }\end{array}$ & $\begin{array}{l}76 \\
34\end{array}$ & $\begin{array}{l}55,91 \\
54,57\end{array}$ & $\begin{array}{l}4249,50 \\
1855,50\end{array}$ & 1260,50 & ,836 \\
\hline Toplam & $\begin{array}{l}\text { Lisans } \\
\text { Y.Lisans }\end{array}$ & $\begin{array}{l}76 \\
34\end{array}$ & $\begin{array}{l}53,85 \\
59,19\end{array}$ & $\begin{array}{l}4092,50 \\
2012,50\end{array}$ & 1166,50 & ,415 \\
\hline
\end{tabular}

Tablo 2'de görüldüğü gibi, araştırmaya katılanların Örgütsel Stres Ölçeğinden almış oldukları puanların, cinsiyet ve eğitim durumu değişkenine göre yapılan Mann Whitney-U testi sonucunda, anlamlı bir farklılık bulunmadığı görülmüştür ( $P>0.05)$. Ancak Örgütsel Stres ölçeği hem cinsiyet değişkeni hem de eğitim durumu değişkenine göre Karar Verme alt boyutunda, cinsiyet değişkeninde erkeklerin, eğitim durumu değişkeninde ise Yüksek Lisans mezunlarının lehinde anlamlı farklılığın oluştuğu görülmüştür. 
Tablo 3. Örgütsel Stres Ölçeği puanlarının yaş değişkenine göre Kruskall Wallis testi sonuçları

\begin{tabular}{|c|c|c|c|c|c|c|c|}
\hline $\begin{array}{l}\text { Alt Bo- } \\
\text { yutlar }\end{array}$ & Yaş & $\mathbf{N}$ & $\begin{array}{c}\text { Sira Orta- } \\
\text { laması }\end{array}$ & $S d$ & $X^{2}$ & $\mathbf{P}$ & $\begin{array}{c}\text { Anlamlı } \\
\text { Fark }\end{array}$ \\
\hline \multirow{5}{*}{ İş Yükü } & $25-$ & 21 & 27,33 & \multirow{4}{*}{3} & \multirow{4}{*}{33,82} & \multirow{4}{*}{, $000^{*}$} & \\
\hline & $26-30$ & 39 & 54,59 & & & & $4-3$ \\
\hline & $31-35$ & 28 & 56,88 & & & & 4-2 \\
\hline & $36+$ & 22 & 82,25 & & & & $4-1$ \\
\hline & 25- & 21 & 54,14 & \multirow{5}{*}{3} & \multirow{5}{*}{0,14} & \multirow{5}{*}{,986 } & \multirow{4}{*}{ Yok } \\
\hline \multirow{4}{*}{$\begin{array}{c}\text { Beceri } \\
\text { Kulla- } \\
\text { nımı }\end{array}$} & $26-30$ & 39 & 56,82 & & & & \\
\hline & $31-35$ & 28 & 55,61 & & & & \\
\hline & $36+$ & 22 & 54,32 & & & & \\
\hline & 25- & 21 & 33,33 & & & & \\
\hline \multirow{4}{*}{$\begin{array}{l}\text { Karar } \\
\text { Verme }\end{array}$} & $26-30$ & 39 & 59,14 & \multirow{4}{*}{3} & \multirow{4}{*}{13,84} & \multirow{4}{*}{, $003^{*}$} & \multirow{4}{*}{$4-1$} \\
\hline & $31-35$ & 28 & 60,77 & & & & \\
\hline & $36+$ & 22 & 63,50 & & & & \\
\hline & 25- & 21 & 58,76 & & & & \\
\hline \multirow{4}{*}{$\begin{array}{l}\text { Sosyal } \\
\text { Destek }\end{array}$} & $26-30$ & 39 & 54,92 & \multirow{4}{*}{3} & \multirow{4}{*}{0,56} & \multirow{4}{*}{,905 } & \multirow[t]{4}{*}{ Yok } \\
\hline & $31-35$ & 28 & 56,66 & & & & \\
\hline & $36+$ & 22 & 51,93 & & & & \\
\hline & $25-$ & 21 & 57,05 & & & & \\
\hline \multirow[t]{3}{*}{ Toplam } & $26-30$ & 39 & 57,08 & \multirow{3}{*}{3} & \multirow{3}{*}{9,72} & \multirow{3}{*}{, $021^{*}$} & \multirow[t]{3}{*}{$4-1$} \\
\hline & $31-35$ & 28 & 59,34 & & & & \\
\hline & $36+$ & 22 & 65,43 & & & & \\
\hline
\end{tabular}

Tablo 3'de görüldüğü gibi, araştırmaya katılanların Örgütsel Stres ölçeğinden almış oldukları puanların, yaş değişkenine göre yapılan Kruskall Wallis testi sonucunda istatistiksel açıdan anlamlı bir farklılık bulunmuştur $(\mathrm{P}<0.05)$. Ayrıca Örgütsel Stres ölçeği iş yükü ve karar verme alt boyutunda da istatistiksel açıdan anlamlı bir fark bulunmuştur.

Tablo 4'de görüldüğü gibi, araştırmaya katılanların Örgütsel Stres ölçeğinden almış oldukları puanların, gelir durumu ve çalışma yılı değişkenine göre yapılan Kruskall Wallis testi sonucunda istatistiksel açıdan anlamlı bir farklılık bulunmamıştır ( $>>0.05)$. Ancak Örgütsel Stres ölçeği alt boyutlarından iş yükü ve karar verme alt boyutunda istatistiksel açıdan anlamlı bir fark bulunmuştur $(\mathrm{P}<0.05)$. 
Tablo 4. Örgütsel Stres Ölçeği puanlarının gelir durumu ve çalışma yılı değişkenine göre Kruskall Wallis testi sonuçlarn

\begin{tabular}{|c|c|c|c|c|c|c|c|}
\hline $\begin{array}{l}\text { Alt Bo- } \\
\text { yutlar }\end{array}$ & Gelir Durumu & $\mathbf{N}$ & $\begin{array}{c}\text { Sira Orta- } \\
\text { lamas1 }\end{array}$ & Sd & $X^{2}$ & $\mathbf{P}$ & $\begin{array}{c}\text { Anlamlı } \\
\text { Fark }\end{array}$ \\
\hline \multirow{5}{*}{ İş Yükü } & $0-1999$ & 11 & 38,95 & \multirow{5}{*}{3} & \multirow{5}{*}{7,55} & \multirow{5}{*}{,056 } & \multirow{5}{*}{ Yok } \\
\hline & 2000-2999 & 10 & 59,85 & & & & \\
\hline & $3000-3999$ & 15 & 42,47 & & & & \\
\hline & $4000+$ & 74 & 60,01 & & & & \\
\hline & 0-1999 & 11 & 71,14 & & & & \\
\hline Beceri & 2000-2999 & 10 & 48,80 & \multirow{4}{*}{3} & \multirow{4}{*}{6,45} & \multirow{4}{*}{,091 } & \multirow[t]{4}{*}{ Yok } \\
\hline \multirow{3}{*}{$\begin{array}{c}\text { Kulla- } \\
\text { nımı }\end{array}$} & 3000-3999 & 15 & 67,23 & & & & \\
\hline & $4000+$ & 74 & 51,70 & & & & \\
\hline & 0-1999 & 11 & 36,95 & & & & \\
\hline Karar & 2000-2999 & 10 & 50,30 & \multirow{4}{*}{3} & \multirow{4}{*}{5,94} & \multirow{4}{*}{,114 } & \multirow{4}{*}{ Yok } \\
\hline \multirow[t]{3}{*}{ Verme } & $3000-3999$ & 15 & 51,70 & & & & \\
\hline & $4000+$ & 74 & 59,73 & & & & \\
\hline & 0-1999 & 11 & 80,05 & & & & \\
\hline \multirow{4}{*}{$\begin{array}{l}\text { Sosyal } \\
\text { Destek }\end{array}$} & 2000-2999 & 10 & 56,60 & \multirow{4}{*}{3} & \multirow{4}{*}{10,67} & \multirow{4}{*}{, $014^{*}$} & \\
\hline & $3000-3999$ & 15 & 65,27 & & & & $4-1$ \\
\hline & $4000+$ & 74 & 49,72 & & & & \\
\hline & 0-1999 & 11 & 66,23 & & & & \\
\hline \multirow[t]{4}{*}{ Toplam } & 2000-2999 & 10 & 52,10 & \multirow{3}{*}{3} & \multirow{3}{*}{1,47} & \multirow{3}{*}{,688 } & \multirow[t]{3}{*}{ Yok } \\
\hline & 3000-3999 & 15 & 55,90 & & & & \\
\hline & $4000+$ & 74 & 54,28 & & & & \\
\hline & Çalışma Yılı & $\mathbf{N}$ & $\begin{array}{c}\text { Sira Orta- } \\
\text { lamas1 }\end{array}$ & Sd & $\mathbf{X}^{2}$ & $\mathbf{P}$ & $\begin{array}{c}\text { Anlamlı } \\
\text { Fark }\end{array}$ \\
\hline & $0-1$ & 18 & 30,11 & & & & \\
\hline İş Yükü & $1-3$ & 42 & 52,87 & & & & $4-3$ \\
\hline & $4-6$ & 26 & 59,79 & 3 & 21,90 &, $000^{*}$ & $4-2$ \\
\hline & $7+$ & 24 & 74,50 & & & & $4-1$ \\
\hline & $0-1$ & 18 & 58,00 & & & & \\
\hline Beceri & $1-3$ & 42 & 56,77 & 3 & & & \\
\hline Kulla- & $4-6$ & 26 & 52,21 & 3 & ,483 & ,923 & Yok \\
\hline nimı & $7+$ & 24 & 54,96 & & & & \\
\hline & $0-1$ & 18 & 32,56 & & & & \\
\hline Karar & $1-3$ & 42 & 56,02 & & & & $4-1$ \\
\hline Verme & $4-6$ & 26 & 62,98 & 3 & 13,34 &, $004^{*}$ & $3-2$ \\
\hline & $7+$ & 24 & 63,69 & & & & \\
\hline & $0-1$ & 18 & 66,64 & & & & \\
\hline Sosyal & $1-3$ & 42 & 52,75 & & & & \\
\hline Destek & $4-6$ & 26 & 51,67 & 3 & 2,097 & ,395 & Yok \\
\hline & $7+$ & 24 & 56,10 & & & & \\
\hline & $0-1$ & 18 & 44,58 & & & & \\
\hline Toplam & $1-3$ & 42 & 55,48 & & & & \\
\hline & $4-6$ & 26 & 54,15 & 3 & 4,39 & ,222 & Yok \\
\hline & $7+$ & 24 & 65,19 & & & & \\
\hline
\end{tabular}




\section{Tartışma}

$\mathrm{Bu}$ araştırmada, büyük kurumsal yapılarda çalışan sedanter bireylerin spor organizasyonlarına katılması sonucunda bireylerde ki örgütsel stres düzeylerinin belirlenmesi amacıyla yapılmıştır. Yapılan bu araştırmada Örgütsel Stres Ölçeğinin cinsiyet ve eğitim durumu değişkenine göre, anlamlı bir farklılık bulunmamıştır ( $>0.05)$. Ancak Örgütsel Stres ölçeği hem cinsiyet değişkeni hem de eğitim durumu değişkenine göre "karar verme" alt boyutunda, "cinsiyet" değişkeninde erkeklerin, "eğitim durumu" değişkeninde ise "yüksek lisans" mezunlarının lehinde anlamlı farklılığın oluştuğu görülmüştür. Literatüre bakıldığında yapılan araştırmayla paralellik gösteren çalışmalar mevcut Göksel ve ark. (2017), Kılıç ve ark. (2013)'nın yaptığı çalışmalarda da benzer sonuçlar göstermektedir. Yine yapılan araştırmada Örgütsel Stres Ölçeği medeni durum değişkenine göre istatistiksel açıdan anlamlı bir farklılık bulunmuş $(\mathrm{P}<0.05)$, ortaya çıkan bu anlamlı farkın evli bireyler lehine olduğu görülmüştür. Ayrıca Örgütsel Stres Ölçeği, “iş yükü” alt boyutunda doğal olarak evli bireyler lehine anlamlı farklılık bulunmuştur. Bu durum bize yaşam koşullarının maddi ve manevi ağırlığı sonucunda artık evli bireylerin bu yükü birlikte üstesinde gelme çabası içinde olduğunu ve özellikle de "iş yükü" alt boyutunda bu farklılığın ön plana çıktığını göstermektedir. Literatüre baktığımızda, Göksel ve ark. (2017)'nın yaptığı araştırmada medeni durum değişkenine göre anlamlı bir fark söz konusu değilken Yurtseven (2016)'nın yaptığı çalışmada ise evli bireylerin örgütsel stres puanlarının daha yüksek olduğu belirtilmiştir. Yine Atalay ve ark. (2015)'nın yaptığ 1 çalışmada eğitim düzeyi yükseldikçe stres düzeyi puanlarında artış olduğu görülmektedir.

Yapılan araştırmada Örgütsel Stres ölçeği, yaş değişkenine göre, istatistiksel açıdan anlamlı bir farklılık bulunmuştur $(\mathrm{P}<0.05)$. Ortaya çıkan bu anlamlı farklılığın 36 yaş ve üzeri bireylerin 25 yaş ve altı bireylere oranla örgütsel stres düzeyinin daha yüksek olduğu görülmektedir. Bu durum bize bireylerin yaş aldıkça hayata dair stres faktörlerinin de arttığını düşündürmektedir. Ayrıca Örgütsel Stres ölçeği "iş yükü" ve "karar verme" alt boyutlarında istatistiksel açıdan anlamlı bir fark bulunmuştur. Bu durum insanların olgunlaştıkça iş yükü ve de karar verme boyutunda tecrübe ve deneyimin etkin bir faktör olduğunu ortaya koymaktadır. Atalay 
ve ark. (2015)'nın yaptığı çalışmada da 36 yaş ve üzeri bireylerin genç bireylere göre daha yoğun olduğu görülmüştür.

\section{Sonuç}

Yapılan araştırmada katılanların Örgütsel Stres ölçeği, gelir durumu ve çalışma yılı değişkenine göre istatistiksel açıdan anlamlı bir farklılık bulunmamıştır ( $\mathrm{P}>0.05)$. Ancak Örgütsel Stres ölçeği alt boyutlarından "iş yükü" ve "karar verme" alt boyutunda çalışma yılı değişkenine göre istatistiksel açıdan anlamlı bir fark bulunmuştur $(\mathrm{P}<0.05)$. Bu durum bize göstermektedir ki bireylerin çalışma yılı arttıkça deneyim kazandığı ve bu doğal durumun sonucu olarak da iş yükü ve karar verme boyutunu etkilediği görülmektedir. Yine gelir durumu değişkenine göre 4000 tl ve üzeri gelire sahip bireylerin "sosyal destek" alt boyutunda anlamlı bir farkın oluştuğu bu durumun bireylerin gelir seviyesi yükseldikçe sosyal sorumluluk düzeyinin arttı̆̆ını ortaya koymaktadır. 


\title{
EXTENDED ABSTRACT
}

\section{Determination of Organizational Stresses For Employees Participated in Corporate League}

\author{
Arda Öztürk - Osman Tolga Togo \\ Pamukkale University - Harran University
}

They are experiencing a greater tension than in today's society. Working life is also one of the biggest reasons for this situation. Banks are because there are various ones there, stopping and using stress to eliminate the negative effects of the inevitable stress. For this reason, the reasons for organizational stress Lazarus, stress when the organization wants to organism, the organization is defined as the situation that exceeds the middle-to-go (Ekmekçi, 2008). Stress is the indispensable union of life. Because it allows people to behave better against stimuli in the room (Eren, 2000).

Organizational stress is a reaction to the external environment that imposes more mental or physical demands on the person as a result of his / her relationship with the environment (Akgündüz, 2006). It can be said that the workplace emerges as a result of physical and mental pressures felt by the worker in the process of fulfilling what is expected of him. According to Yilmaz (2007), organizational stress on employees creates negative effects and reduces their performance in the workplace and negatively affects the safety of themselves and their colleagues in the workplace.

\section{Method}

In this study, it was aimed to determine the perceived organizational stress levels of individuals participating in sports organization working in different units of Ing Bank and Denizbank and to investigate their relationship with some factors.

The universe of the research; All individuals working in different units in the Bank headquarters of İng bank and Denizbank are composed of 110 individuals who work in different units and participated in sports organizations. 


\section{Data collection}

In this study, a questionnaire which was developed by Theorell et al. In 1988 and translated into Turkish by Yıldirım et al. The questionnaire was translated into Turkish and re-arranged with expert opinions. The eigenvalues of 14 items analyzed were grouped under 4 factors greater than 1 . The first factor is from items $14,15,17,13,16$ and 12 , the second factor is from items 2,1 and 3 , the third factor is from items 7,8 and 6 , and the fourth factor is 10 and 11 .

\section{Data Analysis}

The data were analyzed by SPSS 21.0 package program. Percentage and frequency distributions of the data obtained from the Organizational Stress scale were excluded. Kruskal Wallis Test was applied. Data analysis was evaluated at $95 \%$ confidence interval and $p<0.05$ significance level.

\section{Findings}

The results of the data were tested and the data were not normal. As a result Mann Whitney U Test was used for the paired comparisons and Kruskal Wallis test was used for mul-tiple comparisons. In the analysis of the data, statistical results were found significant at $p<0.05$ significance level. At the end of the research, Organizational Stress Scale; In the Decision Making sub-dimension according to the gender variable and educational status variable, it was seen that there was a significant difference in the gender variable in the variables of gender and in the educational variable variable in favor of the MA graduates. $(\mathrm{P}<0.05)$.

\section{Discussion}

In this study, it was aimed to determine the organizational stress levels of sedentary individuals working in large institutional structures as a result of participation in sports organizations. In this study, no significant difference was found according to gender and educational status of Organizational Stress Scale ( $\mathrm{P}>0.05)$. However, there was a significant difference in the "decision making" sub-dimension according to both the gender variable and the educational status variable, in favor of the inde gender, variable in favor of the male 
and "graduate" graduates in the "educational status" variable. When the literature is examined, there are studies that show parallelism with the study Göksel. (2017), Kılıç. (2013) shows similar results. In the study, a statistically significant difference was found according to the marital status variable of Organizational Stress Scale $(\mathrm{P}<0.05)$, it was found that this significant difference was in favor of married individuals. In addition, a significant difference was found in favor of married individuals in Organizational Stress Scale, "workload" subscale. This situation shows us that as a result of the material and spiritual weight of living conditions, married individuals are now trying to overcome this burden together and this difference especially comes into prominence in the boyut workload "sub-dimension.

\section{Results}

No statistically significant difference was found between the participants' Organizational Stress Scale, income status and working year variables $(\mathrm{P}>0.05)$. However, there was a statistically significant difference in the workload "and" decision making "sub-dimensions of the Organizational Stress Scale sub-dimensions according to the working year variable $(\mathrm{P}<0.05)$. This shows us that individuals gain experience as the working year increases and as a result of this natural situation affects the workload and decision-making dimension.

\section{Kaynakça / References}

Akgündüz, S. (2006). Örgütsel stres kaynaklarının çalı̧anların iş tatmini üzerindeki etkisi ve banka çalışanları için yapılan bir araştırma. Yüksek Lisans Tezi, Dokuz Eylül Üniversitesi, Sosyal Bilimler Enstitüsü, İzmir.

Arıkan, G. (2019). Spor lisesi öğrencilerinde okula aidiyet duygusu. Journal Smart Magazine, 5, 40-44.

Atalay, A. Yücel, S. A. Korkmaz, M. (2015). Gençlik hizmetleri ve spor il müdürlükleri çalışanlarının örgütsel stres düzeylerinin belirlenmesi. Ankara Üniversitesi Spor Bil Fak, 13(1), 17-28.

Aydın, Ş. (2004). Örgütsel stres yönetimi. Dokuz Eylül Üniversitesi Sosyal Bilimler Enstitüsü Dergisi, 6(3), 49-74. 
Ekmekçi, R. (2008). Basketbol hakemlerinin stres kaynakları ile stresle başa çıkma yöntemlerinin tespiti ve önleyici yönetsel uygulamalarn geliştirilmesi. Yayımlanmamış Doktora Tezi. Abant İzzet Baysal Üniversitesi Sosyal Bilimler Enstitüsü, Bolu.

Eren, E. (2000). Örgütsel davranış ve yönetim psikolojisi, 6. Baskı, İstanbul: Beta Yayınları, İstanbul, s.112, 275-292.

Eskin, M. Harlak, H. Demirkıran ve F. Dereboy, Ç. (2013). Algılanan stres ölçeğinin türkçeye uyarlanması: güvenirlik ve geçerlik analizi. New/Yeni Symposium Journal,51(3), 132-140.

Göksel, G. A., Caz, Ç., Yazıcı, Ö. F. ve İkizler, H. C. (2017). Examination of the relationship between organizational stress and employee performance: A research on staff working on provincial directorate of youth and sports. Journal of Education and Learning, 6(1), 322-329.

Kılıç, R., Yumuşak, S. ve Yıldız, H. (2013). Banka çalışanlarının maruz kaldıkları bireysel ve örgütsel stres kaynakları arasındaki ilişkilerin incelenmesi. Osman Gazi Üniversitesi İ̈BF Dergisi, 8(2),71- 92.

Soysal, A. (2009). İş yaşaminda stres. ÇEİS Dergisi, 23(3), 17-40.

Theorell, T. Perski, A. Åkerstedt, T. ve ark. (1988). Changes in job strain in relation to changes in physiological state. Scand J Work Environ Health, 14,189-196.

Yıldırım, Y., Taşmektepligil, M. Y. Ve Üzüm, H. (2011). Kısa versiyon örgütsel stres ölçeğinin Türkçeye uyarlanması. Selçuk Üniversitesi Spor Bilimleri Dergisi, 13(1), 103-108.

Yılmaz, Z. (2007). Ilköğretim okulu yöneticilerinin iş doyumları ile örgütsel stres kaynakları arasındaki ilişki. Yüksek Lisans Tezi, Gaziantep Üniversitesi Sosyal Bilimler Enstitüsü, Gaziantep.

Yurtseven, C. N. (2016). Spor işletmelerindeki yöneticilerin örgütsel stres kaynaklarının incelenmesi, Yayınlanmamış Yüksek Lisans Tezi, İstanbul Üniversitesi Sosyal Bilimler Enstitüsü, İstanbul.

\section{Kaynakça Bilgisi / Citation Information}

Öztürk, A. ve Togo, O. T. (2019). Şirketler ligine katılan iş görenlerin örgütsel streslerinin belirlenmesi. OPUS-Uluslararası Toplum Araştırmaları Dergisi, 13(19), 1376-1389. DOI: 10.26466/opus.581146 